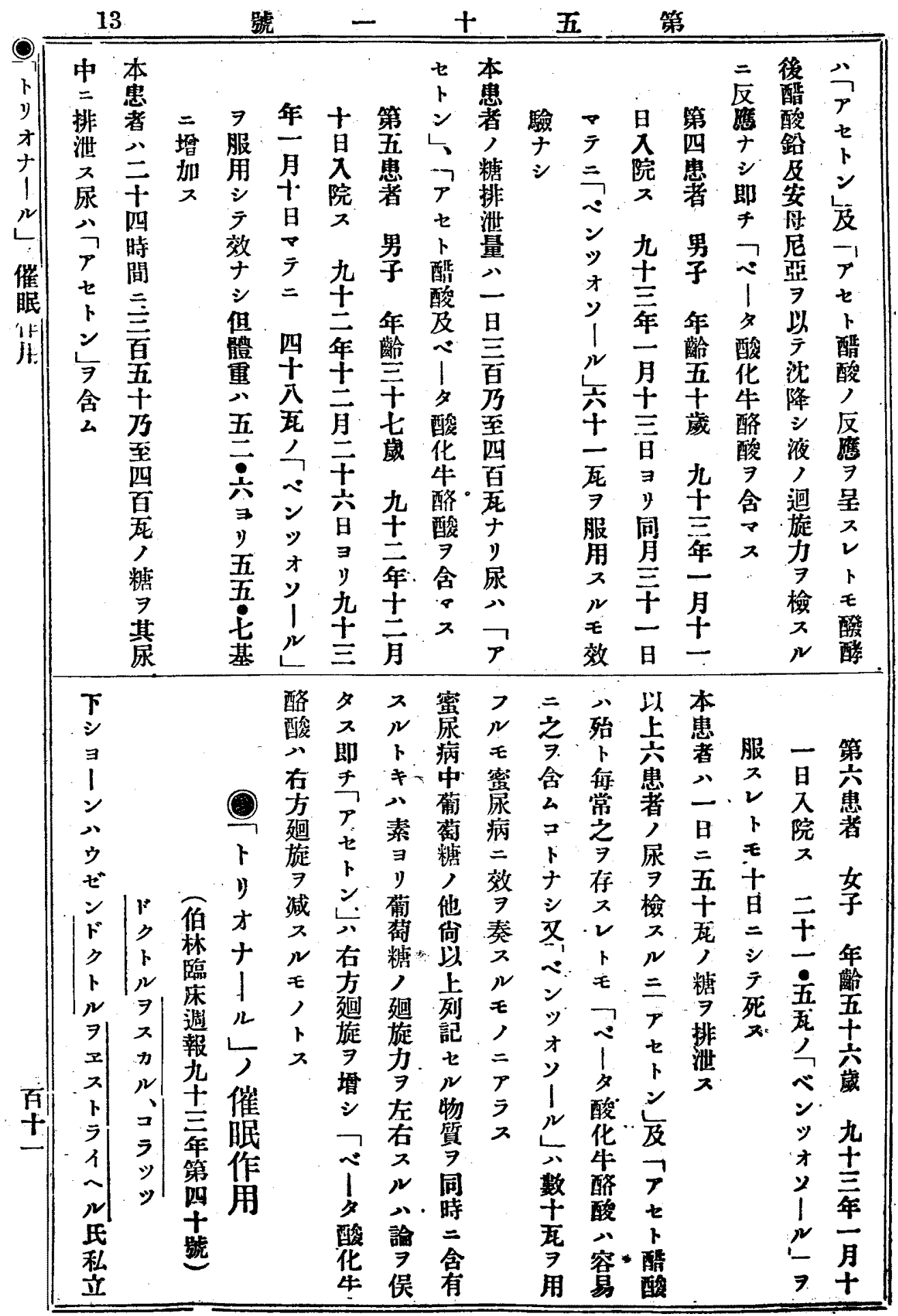




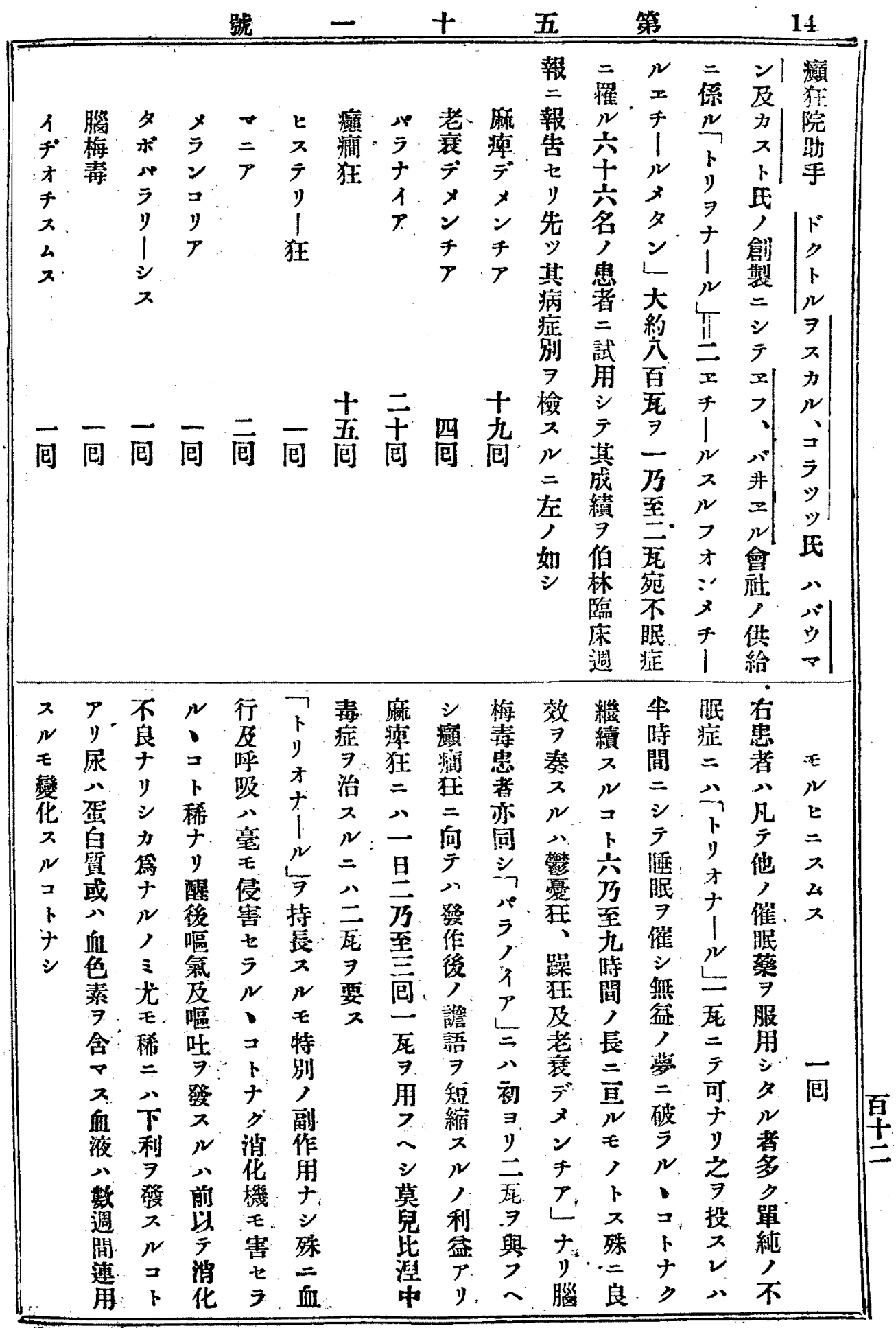


$-$

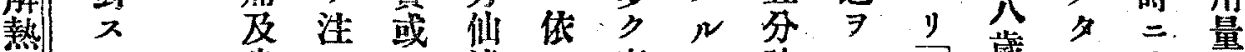

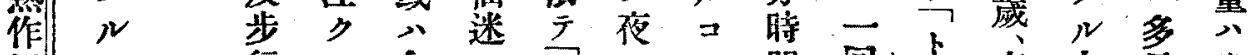

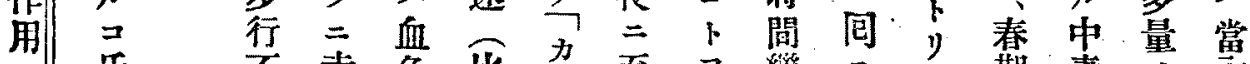

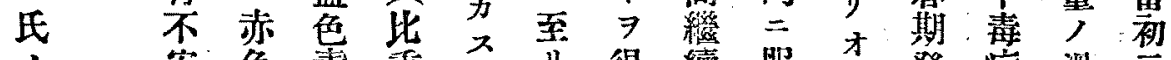
結 安

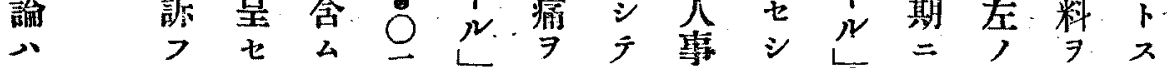

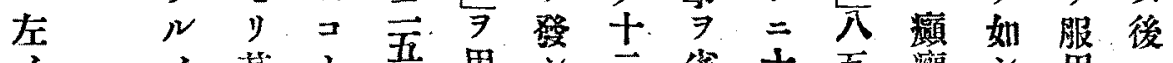

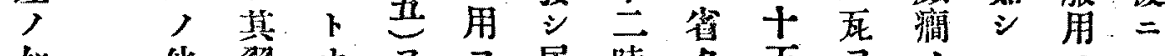
如他一侸ナ

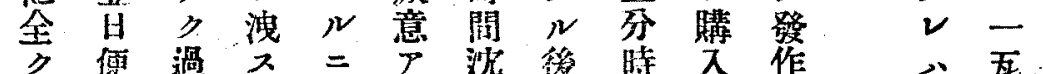

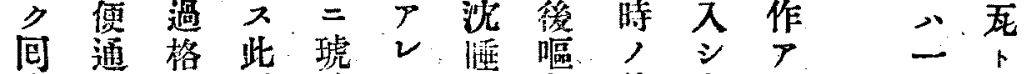

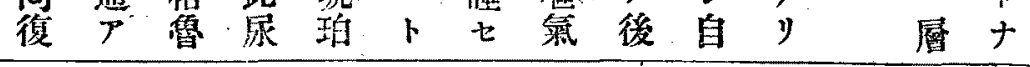

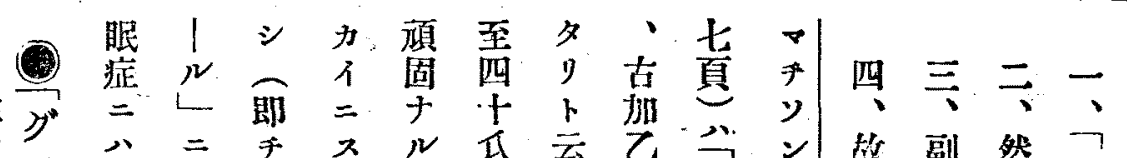
用アフ三三比該ム

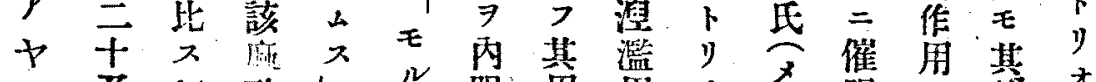
コ.乃 1 至

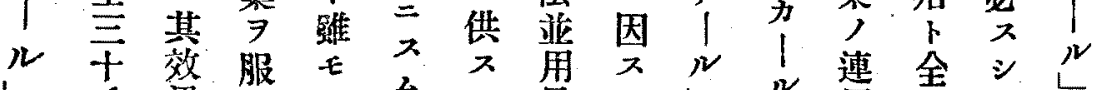

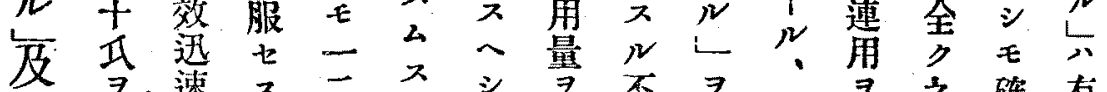

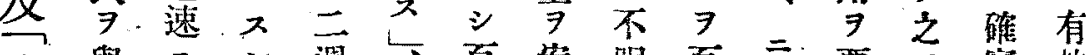
夕 與 二

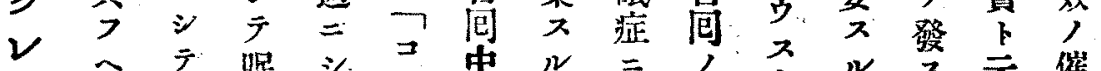

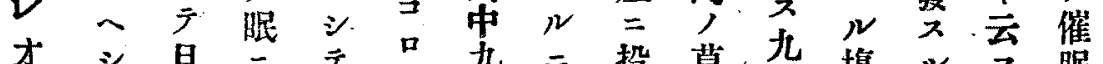

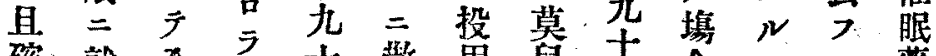

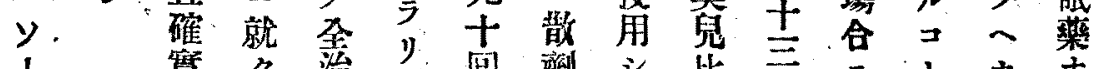

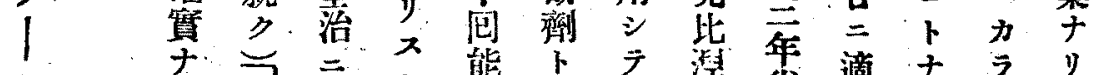

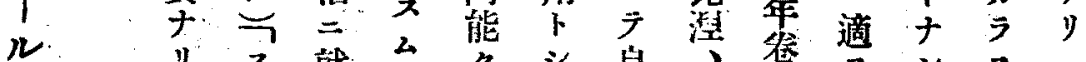

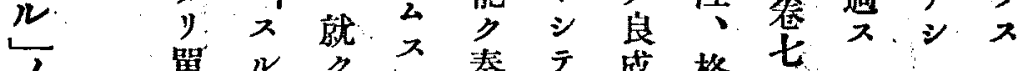
解 純、フ

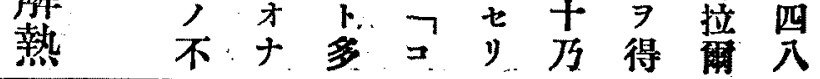




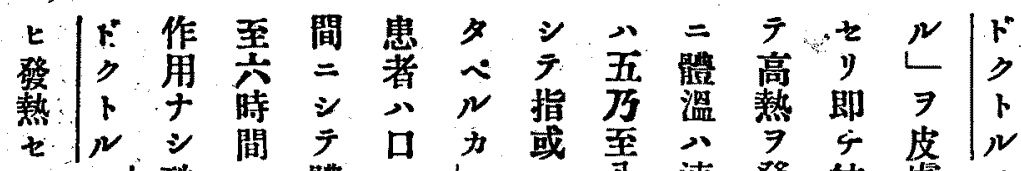

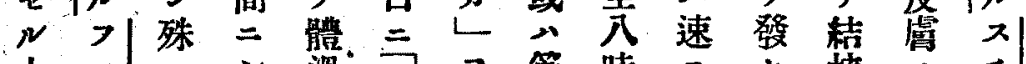

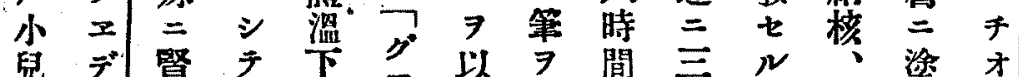

兒デ腎テ下分以

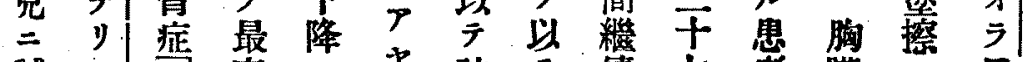

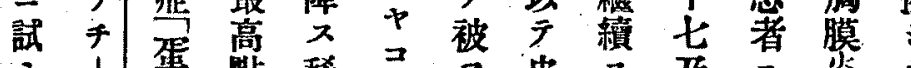

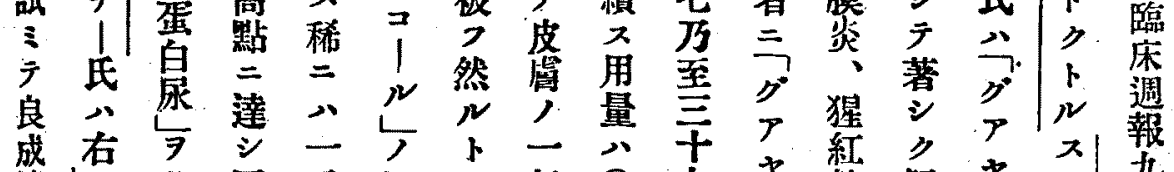

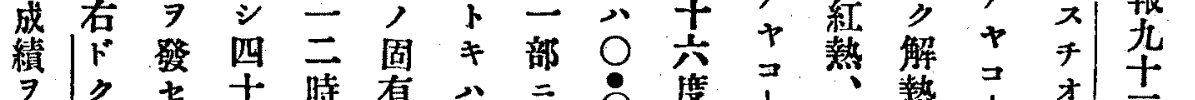

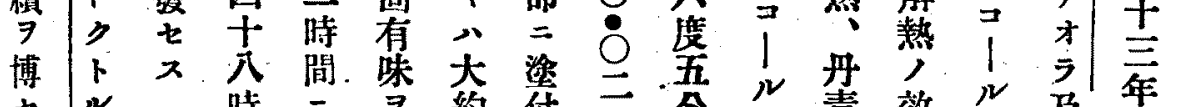

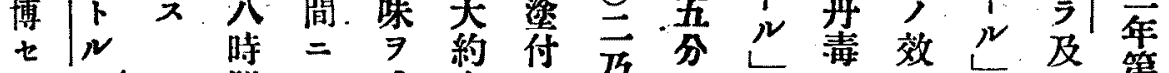

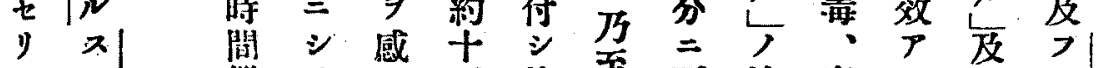

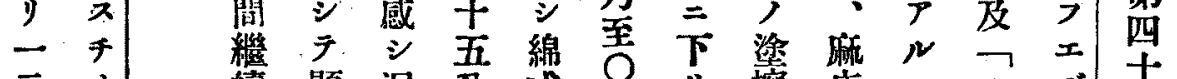

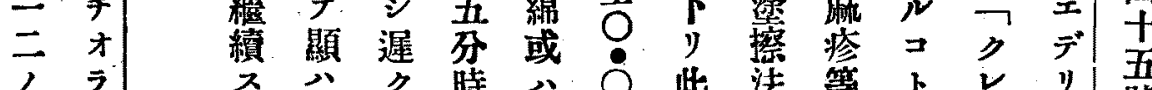

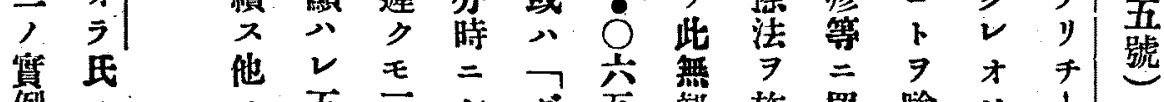

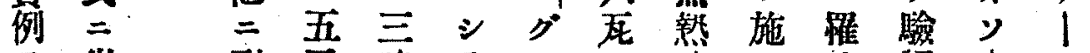

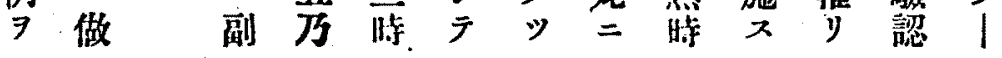

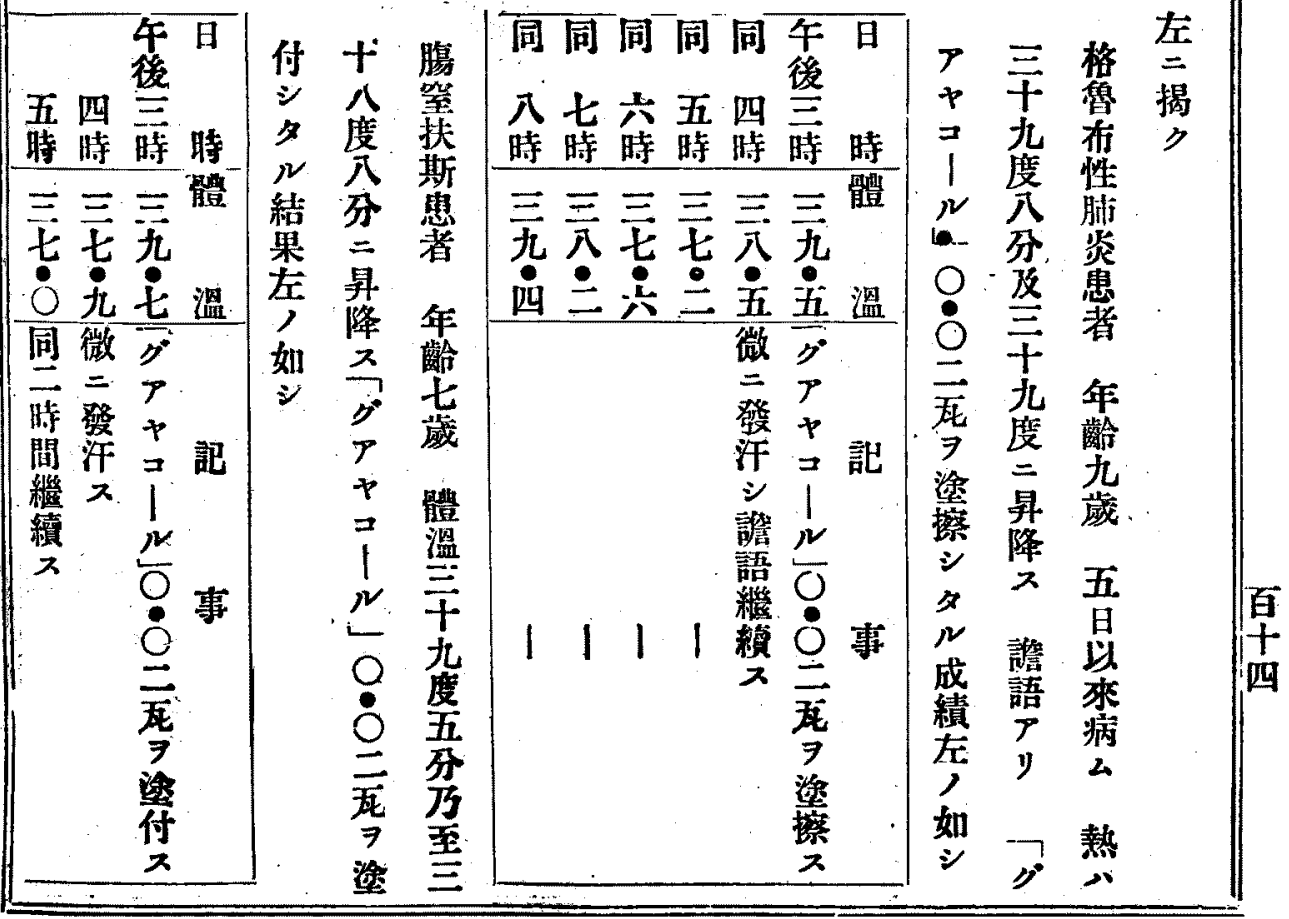




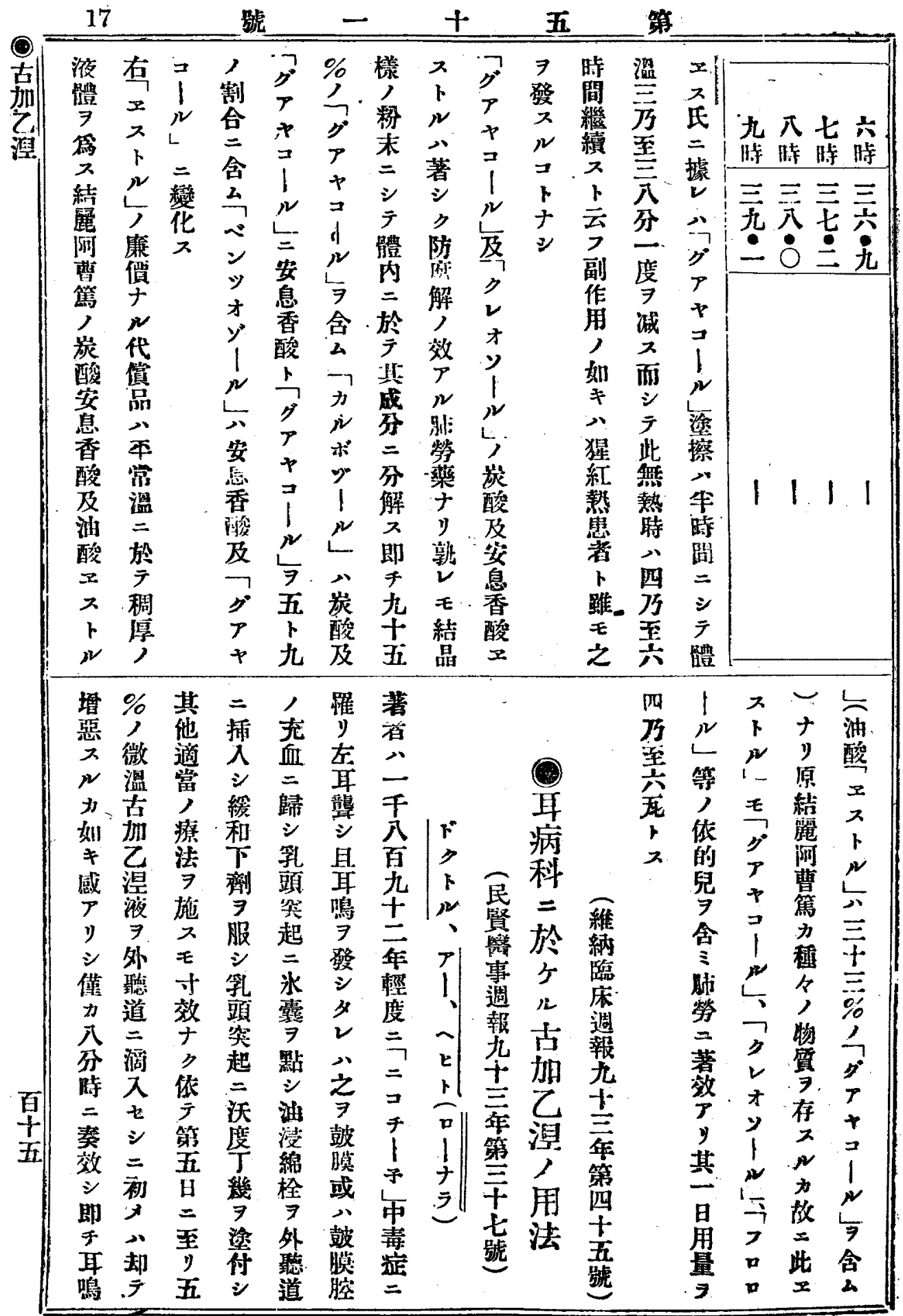




\section{介 㺓}

郝士右

刺亞 搨外或五溶

納鉛 酸聽 分分和

林 華

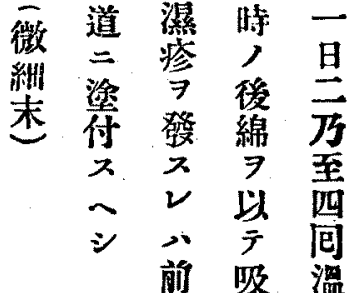

五: ? 燕 取

家瓵吾

液的

滴

前道

後

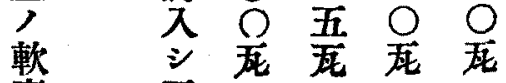

古
古
左㯖

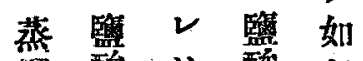

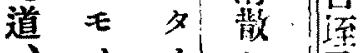

锱 酸义酸 シ 鼔

悂埧

膜 三 氏聽

及 法官

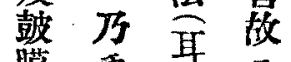

膜社䅗復

膑到等

各 公報 当

克南克

㐬 妿百案

症湟杂穼

有蛋年少

效 $v$ 第 $=$

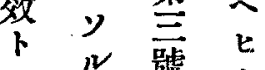

七

) $\neq=$ 氏

其㫛擬療

處

方外少

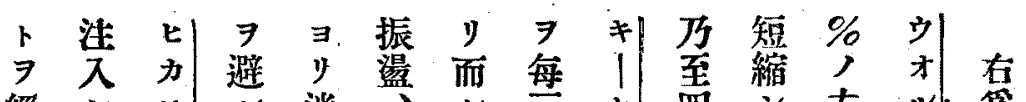

經

驗 $夕 1$ =廓人

○坛 $心=$ 事其至心膘乙

古》後當向不角至

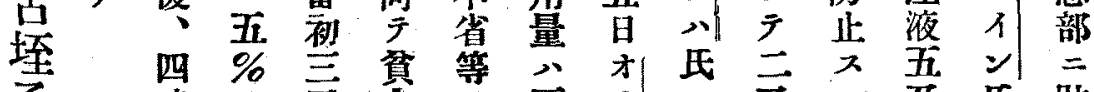

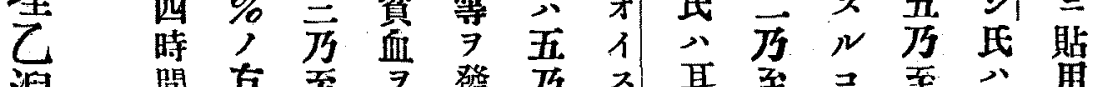

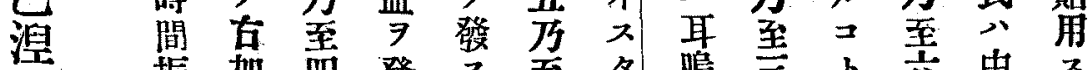

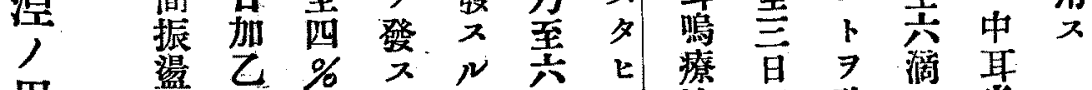

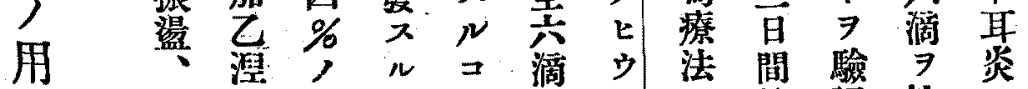

法㛺液液

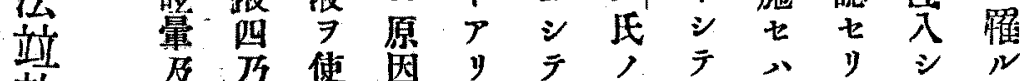

效居㭆使因 y

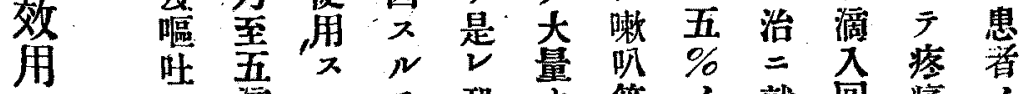

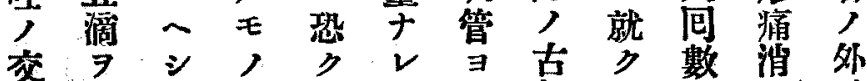

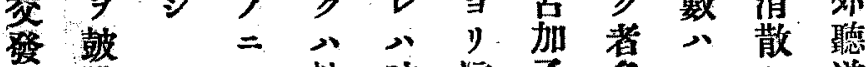

入膜 シ 鼔墑乙多一檤

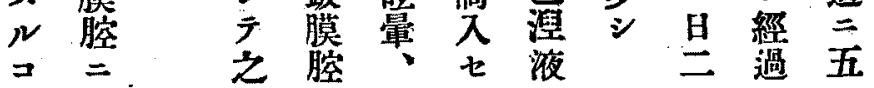




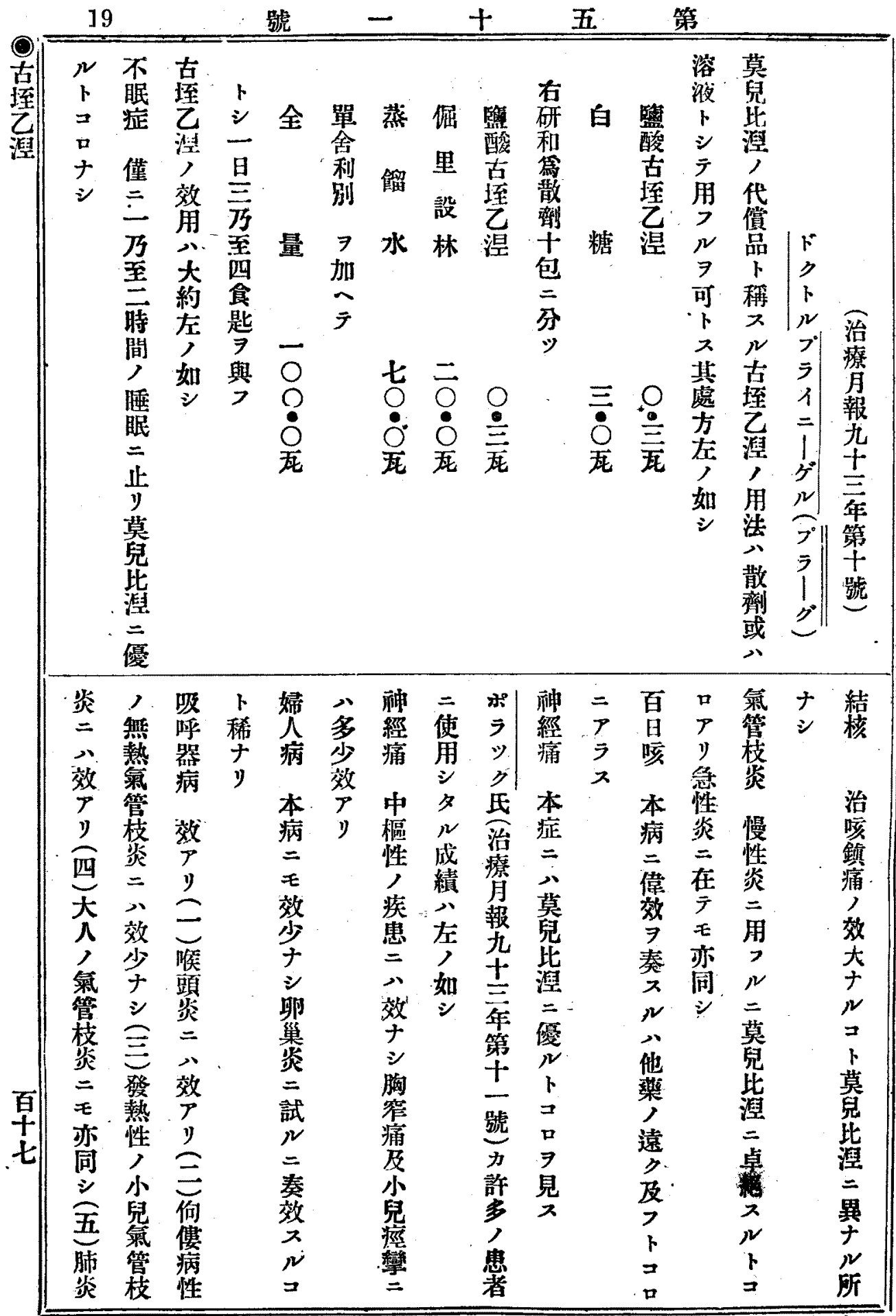




\begin{tabular}{|c|c|c|c|c|c|c|c|c|c|c|c|c|c|c|c|}
\hline & & & & 號 & & - & & + & & 五 & 第 & & & 20 & \\
\hline 那 & ザ| & $N$ & $=$ & 7 & ح & 藥 & & & & & & & 膜 & $=$ & 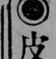 \\
\hline 篤 & 1 & F & $\bar{J}$ & 生 & サ & 物 & & & & & & & 焂 & $\because$ & $\frac{1 x}{\Gamma}$ \\
\hline 熘 & 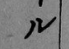 & $\neq$ & 䧕 & $\bar{x}$ & $v$ & $J$ & & & & & & & $=$ & 掌 & 汼 \\
\hline 謨 & $>$ & $\leadsto$ & 灼 & N & 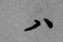 & 溶 & & & & & 0 & $\therefore$ & 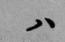 & 兒 & $\vec{\lambda}$ \\
\hline 液 & $x$ & 决 & x & $\exists$ & 徒 & 液 & & & (2) & & 0 & 避 & 效 & 比 & $=$ \\
\hline 1 & $N$ & シ & $\sim$ & F & $=$ & 例 & & & 皮 & & 0 & 月 & † & 溜 & 關 \\
\hline 皮 & Fi & テ & シ & $r$ & 疼 & $>$ & & & & & & & シ & I & $\pi$ \\
\hline 下 & 氏 & 膿 & $\bar{t}$ & !) & 痛 & 案 & & & & & & & t & 右 & N \\
\hline 泩 & 八 & 瘍 & 藥 & 故 & $\exists$ & 知 & & & 注 & & & - & 芹 & $=$ & 泩 \\
\hline 入 & 法 & 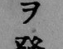 & 液 & $=$ & 發 & 必 & & & 入 & & & 䇠 & 奣 & 出 & 意 \\
\hline 必 & 到 & $\begin{array}{l}\text { 嗮 } \\
\text { x }\end{array}$ & 汼 & 射 & ג & $\begin{array}{l}\text { 㷊 } \\
\Rightarrow\end{array}$ & & 3 & & 治 & 0 & 回 & 率 & 2 & (2) \\
\hline x & $\begin{array}{l}\text { 泶 } \\
\end{array}$ & $\hat{v}$ & 入 & 㗊 & 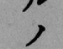 & 皮 & ザ| & 治 & 關 & 摺 & $\underline{0}$ & 月 & $\begin{array}{l}\text { 捚 } \\
=\end{array}$ & 1 & 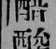 \\
\hline 膿 & 1 & , & $=$ & 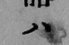 & ミ & T & 1 & 登 & $\pi$ & 召 & $\Omega$ & & $\therefore$ & 能 & 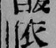 \\
\hline 愓 & 浙 & 虞 & 先 & 必 & ナ & $=$ & 2 & 垱 & ル & tix & 0 & & 吕: & 八 & 的 \\
\hline 7 & 酸 & ナ & $\bar{y}$ & $\pi$ & ラ & 注 & 7 & th & 泣 & + & 0 & $\rightarrow$ & 效 & サ & 兒 \\
\hline 婊 & 加 & シ & 必 & 消 & 조 & 入 & 조 & + & 望 & $\stackrel{1}{\equiv}$ & 0 & & 最 & $N$ & 1 \\
\hline 橃 & 熘 & & 주 & 毒 & 或 & $\pi$ & $N$ & $\doteq$ & 意 & 年 & $\overline{1}$ & & $\begin{array}{l}\mathcal{E} \\
+\end{array}$ & 堭 & 興 \\
\hline ᄌ & 誢 & & 叐 & シ & 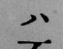 & $N$ & & 年 & & 第 & 1 & & $\underset{+}{\text { 太 }}$ & 谷 & 奮 \\
\hline E & 证 & & 泇 & $\overparen{0}$ & 不 & 站 & & 第 & & \pm & 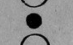 & 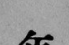 & 1) & y & 性。 \\
\hline ; & 憵 & & $\sim$ & , & j & 意 & & + & & $\overrightarrow{u, t}$ & & 平 & & 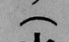 & \\
\hline P & 砧 & & シ & 燈 & 膿 & $\Rightarrow$ & & 斻 & & " & & & & 枀 & \\
\hline 七 & 酸 & & 然 & 上 & 瘍 & 加 & & & & & & & & 腦 & \\
\hline 䓔 & $=$ & $E$ & 夕 & 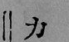 & x & 亞 & & & & シ & & 四 & シ & 古 & \\
\hline 者 & 至 & 听 & 虛 & 7 & $\pi$ & 薾 & & & & 力 & 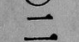 & & & 垤 & \\
\hline М & ラ & 吸 & 脱 & 1 & $卜$ & 䈃 & & & & 使 & & & & 乙 & \\
\hline 中 & $\pi$ & 7 & 症 & 厶 & IV & 保 & & & & 用 & 0 & & & 汪 & \\
\hline 筫 & & 侵 & $=$ & 5 & L & 㸗 & 1 & & (9) & 前 & $\dot{0}$ & 年 & & 監 & \\
\hline$\frac{\text { 量 }}{7}$ & & $\begin{array}{l}\text { 蛪 } \\
\text { ス }\end{array}$ & 用 & 中 & $\begin{array}{c}7 \\
M\end{array}$ & $\begin{array}{l}\text { 飲 } \\
\text { 为促 }\end{array}$ & & & 俵 & 樂 & 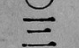 & & & 酸 & \\
\hline 動 & & N & 其 & $\therefore$ & ज & $\begin{array}{l}\text { 枿 } \\
\text { 中 }\end{array}$ & & & 酸 & $\begin{array}{l}\text { 依 } \\
\Rightarrow\end{array}$ & 0 & & & 㖪 & \\
\hline 物 & & , & 效 & 0 & 最 & $=$ & & & 依 & 者 & $\dot{\circ}$ & $f$ & & , & \\
\hline 1 & & 罂 & 用 & • & 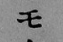 & 含 & & & 的 & 泓 & 四 & & & 用 & \\
\hline 静孚 & & 點 & 7 & 六 & 有 & $\Delta$ & & & $\theta$ & シ & 1 & & & 量 & \\
\hline 洆 & & $P$ & 按 & 九 & 力 & $\bar{x}$ & & 治 & & $\bar{\jmath}$ & 0 & & & - & \\
\hline$\overline{0}$ & & 2 & $\pi$ & 五 & ナ & x & $F$ & 瘵 & & 每: & $\dot{0}$ & 年 & & 日 & \\
\hline$\therefore$ & & P & $N$ & $\%$ & y) & 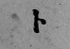 & ? & 月 & 骨形 & 包 & 五. & & & 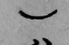 & \\
\hline 无 & & $\bar{\zeta}$ & $\overline{\text { 称 }}$ & 天 & $x$ & $\frac{N}{2}$ & 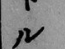 & 報 & 舊 & $\underset{7}{2}$ & 0 & & & 各 & \\
\hline 戌 & & 洲 & 醉 & 往 & 其 & 中 & $\eta_{1}$ & $\underset{+}{九}$ & カ & 免 & O) & 大 & & 年 & 皇 \\
\hline 鸣 & & $\eta$ & 迷 & 時 & 含 & 間 & ラ & $\stackrel{T}{=}$ & & 力 & 入 & & & 竗命 & $\pi$ \\
\hline 皮 & & 嬊 & 朦 & 八 & 量 & 泾 & ウ & $\overrightarrow{x^{\prime}}$ & & $v$ & $\hat{i}$ & & & $=$ & 内 \\
\hline 电 & & 用 & $?$ & 現 & 》 & 7 & 1 & 第 & & タ & 0 & & & 從 & \\
\hline & & $\bar{A}$ & 力 & 今 & ジ & 그 & り & 九 & & !) & - & $\Lambda$ & & $\underline{L}$ & \\
\hline 0 & & 证 & P & $\exists$ & $\stackrel{\downarrow}{\imath}$ & 1 & 1. & 號 & & \pm & $=$ & & & 告, & \\
\hline 主 & & $N$ & $P$ & 䚄 & 1 & $N$ & $\varepsilon$ & & & $\vec{\gamma}$ & & & & 如 & \\
\hline & & & & & & & & & & & & & & & \\
\hline
\end{tabular}




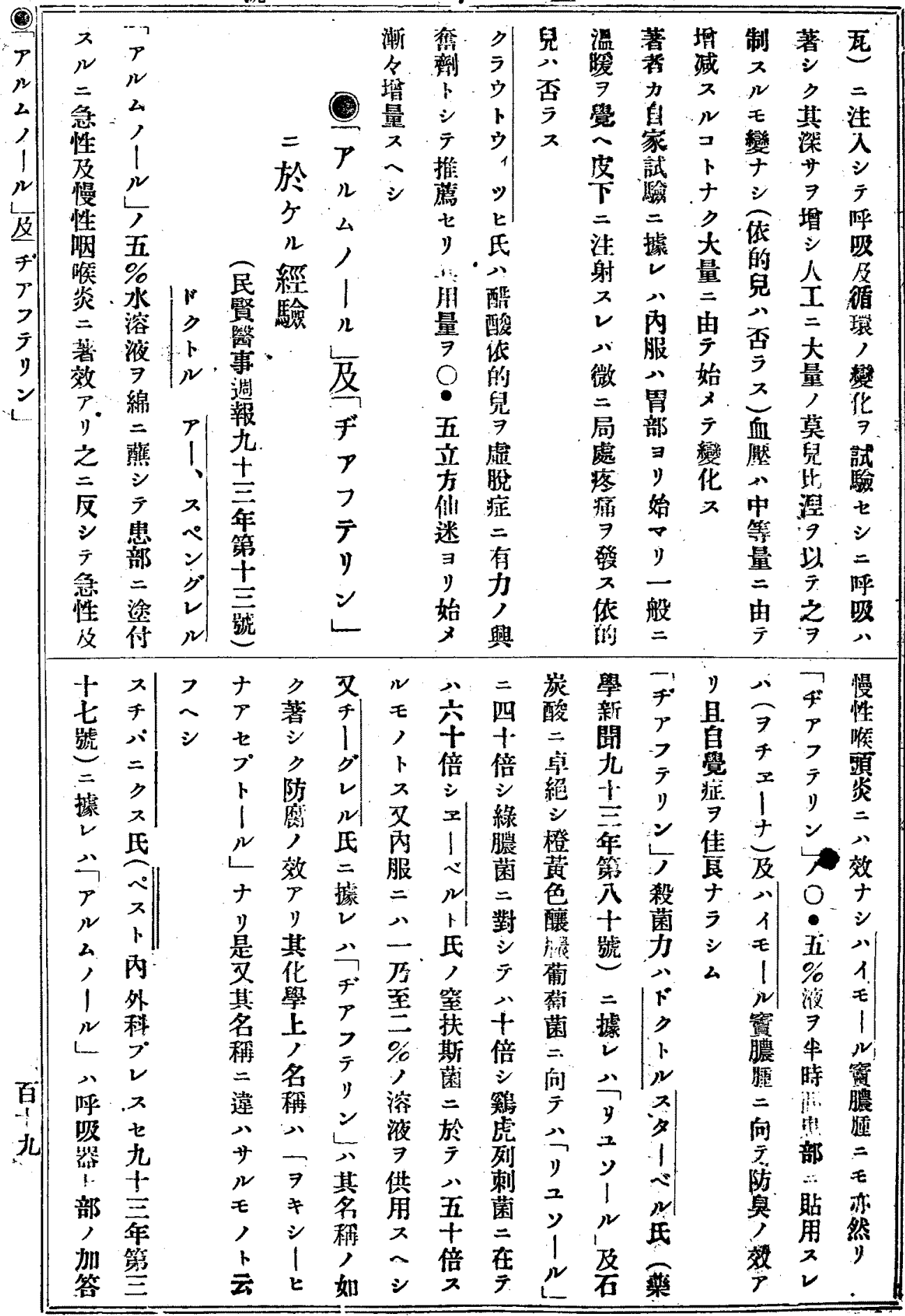




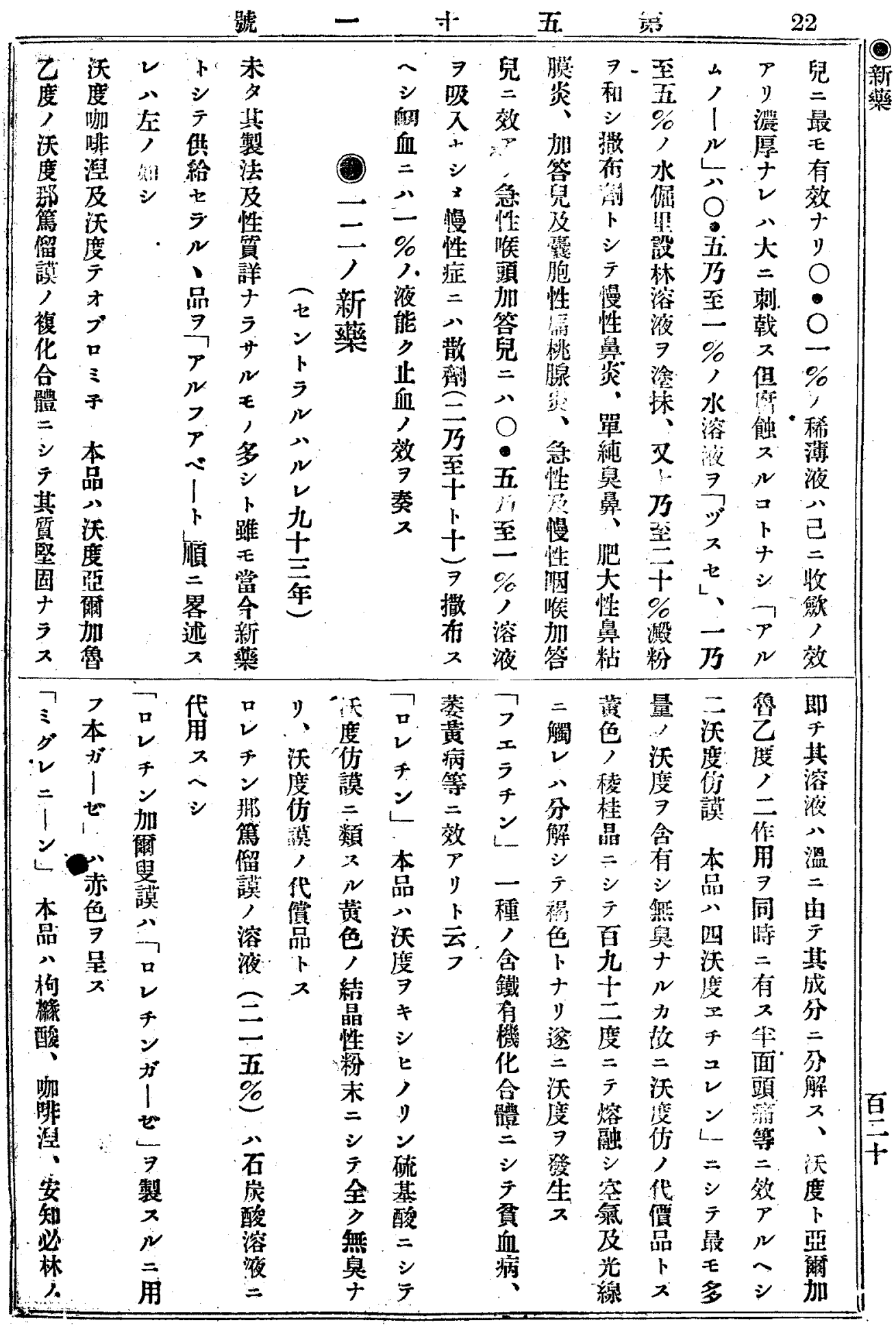

